OPEN ACCESS

Edited by:

Chun Yang

Nanjing Medical University, China

Reviewed by:

Tom Kingstone,

Keele University, United Kingdom

Kai Zhang,

Chiba University, Japan

*Correspondence:

Luis Pinel

Ipine/@cop.es

Specialty section:

This article was submitted to Mood and Anxiety Disorders,

a section of the journal

Frontiers in Psychiatry

Received: 02 May 2020

Accepted: 19 October 2020

Published: 25 November 2020

Citation:

Pinel L, Perez-Nieto MA, Redondo M,

Rodríguez-Rodríguez $L$ and León $L$

(2020) Anxiety, Reinforcement

Sensitivity and Social Context in

Accepting the Experience of Pain Among Rheumatoid Arthritis Patients.

Front. Psychiatry 11:554990.

doi: 10.3389/fpsyt.2020.554990

\section{Anxiety, Reinforcement Sensitivity and Social Context in Accepting the Experience of Pain Among Rheumatoid Arthritis Patients}

\author{
Luis Pinel ${ }^{1 *}$, Miguel A. Perez-Nieto ${ }^{1}$, Marta Redondo ${ }^{1}$, Luis Rodríguez-Rodríguez ${ }^{2}$ and \\ Leticia León ${ }^{1}$ \\ ${ }^{1}$ Faculty of Education and Health, Camilo José Cela University, Madrid, Spain, ${ }^{2}$ Rheumatology Service, Hospital Clínico \\ Universitario San Carlos, Madrid, Spain
}

Background: Acceptance has become one of the most widely studied processes regarding chronic pain because of its ability to influence participants' adaptation and coping responses. Leading researchers have found relationships between variables such as anxiety, reinforcement sensitivity, and the responses of the participants' environment to their behavior and acceptance. In contrast, few studies have been found that investigate the variables that predict the acceptance of pain. This study has set out to explore the relationships between pain-related anxiety, sensitivity to contingencies, and the punishment responses of significant people toward pain behaviors regarding pain acceptance.

Methods: With a view to fulfilling this purpose, a cohort of 62 participants with rheumatoid arthritis was chosen, and the subjects were assessed through the following self-report measures: Chronic Pain Acceptance Questionnaire, CPAQ; Pain Anxiety Symptoms Scale, PASS-20; The Sensitivity to Punishment and Sensitivity to Reward Questionnaire, SPSRQ, and The West Haven-Yale Multidimensional Pain Inventory, WHYMPI. The study's initial objectives were achieved by means of a stepwise multiple linear regression analysis.

Results: The linear regression analyses revealed a negative and significant correlation between anxiety, reinforcement sensitivity, and the significant persons' responses to pain behaviors and pain acceptance.

Conclusion: The results suggest that the identification of these variables might be important for addressing these participants' pain. Finally, the discussion focuses on our findings' implications as regards their use in clinical practice.

Keywords: mindfulness, cognitive behavioral therapy, social influences, reinforcement sensitivity, anxiety, acceptance, chronic pain 


\section{INTRODUCTION}

Chronic pain has latterly become an increasingly serious health issue, as reflected by the new steps taken by the World Health Organization, which has now classified this experience as a major illness (1). The foremost epidemiological studies indicate that chronic pain is highly prevalent worldwide (2-4). Its most serious consequences include impacting upon the quality of life of participants and their families, negative psychological effects, the disability it causes, problems associated with the loss of productivity at work, and the high socio-economic costs incurred by the health system (5-9). Therefore, and in view of these circumstances, it is understandable that chronic pain is now considered a major public health issue (10), becoming a key study topic for leading researchers in the field.

Acceptance has been one of the more widely studied pain-related variables in recent years, as it has rapidly become a significant process for the applied clinical context because of its ability to influence the manner in which participants adapt to and cope with the experience of responding to pain (11-17). On a theoretical level, we are dealing with a complex construct that scholars have interpreted differently (16). Nevertheless, the acceptance of pain has traditionally been defined as an individual's constant readiness to experience pain (thoughts, feelings, sensations, etc.) without offering any resistance, while channeling their behavior toward valuable goals and objectives (11). According to McCracken (16), this definition has two vital components for its understanding: openness or receptivity to pain, and involvement in activities. The component of openness means surrendering to sensorial aspects, to pain-related feelings, thoughts, and emotions. The second component of involvement refers to a subject's commitment to tailor their behavior according to their values and continue with their everyday activities despite the pain. Based on this conceptualization as our reference framework, we have found numerous studies that relate the acceptance of pain to more adaptive coping, being associated with a lower emotional, physical, and social function $(11,13,18-22)$, a lower level of reported pain (23-25), less disability (26), and a reduced use of medication (12). Along these same lines, we find solid evidence to show how clinical interventions based on the acceptance of pain, such as acceptance and commitment therapy (ACT) (27) or mindfulness-based interventions (MBIs) (28), are more effective than processes already in place (29-34). The data available have shown that acceptance is a highly important variable in chronic pain, both at theoretical level and in the field of applied clinical treatment; nevertheless, we have found very few studies that have addressed the psychological variables that might predict higher levels of

\footnotetext{
Abbreviations: ACT, Acceptance and Commitment Therapy; AMAPAR, Association of Participants with Rheumatoid Arthritis; AS, Anxiety Sensitivity; BAS, Behavioral Approach/Activation System; BIS, Behavioral Inhibition System; CBT, Cognitive Behavioral Therapy; CPAQ, Chronic Pain Acceptance Questionnaire; MBIs, Mindfulness-based interventions; PASS-20, Pain Anxiety Symptoms Scale; SP, Sensitivity to punishment; SPSRQ, The Sensitivity to Punishment and Sensitivity to Reward Questionnaire; STR, Sensitivity to reward; WHO, World Health Organization; WHYMPI, The West Haven-Yale Multidimensional Pain Inventory.
}

pain acceptance. Finding these predictors will help to improve the process of selecting the treatment to be followed with these participants.

Anxiety has been described in the literature as a significant factor in acceptance processes in different samples of participants with chronic pain. High levels of pain-related anxiety have therefore been associated with lower levels of openness toward the same, and less involvement in activities by the sufferer; in other words, there seems to be a strong, negative relationship with acceptance (11-13, 21, 35-37). Elsewhere, we encounter studies that address anxiety sensitivity (AS), which has been defined as a trait that predisposes someone to experience a fear of pain and develop anxiety disorders (38). Several scholars have posited that through its predisposition to the fear of pain, AS is directly related to the adoption of escape or avoidance behaviors (39-41). Experiential avoidance is a key pattern of behavior that is located at the other extreme from acceptance (42), whereby it may be argued that AS is indirectly related to the acceptance of this feeling. When we consider the findings of these studies as a whole, they all suggest that anxiety plays a crucial role as a predictor of low acceptance in contexts of chronic pain.

In addition, and in this same vein, there are two known neuropsychological systems that can impact upon avoidance and approach behaviors: the Behavioral Approach/Activation System (BAS) and the Behavioral Inhibition System (BIS). The most widely cited theory of the different approach-avoidance models is Reinforcement Sensitivity Theory $(43,44)$. This model has recently been reviewed within the field of chronic pain [to read the review, see (45)]. This model indicates that the guidelines for behavioral approach or avoidance in certain situations depend on contextual keys (internal or external), which predict the probability of receiving a reward or a punishment (46). The BAS is therefore triggered by the presence of keys that indicate the possibility of obtaining a reward, or of eliminating or reducing the likelihood of an aversive stimulus, while the BIS is triggered by the presence of keys that predict a punishment (e.g., pain, disability, catastrophic thoughts, and anxiety). Numerous researchers have found that participants with chronic pain record more BIS activity and less of BAS (47-51). These systems are in some way mutually inhibited, and their alternance can be explained by sensitivity in the presence of the aversive or appetitive stimulus (52). We have found certain studies that report that these participants are more sensitive to reinforcement than control groups $(47,53)$. An analysis of this information is expected to show that sensitivity to reinforcement and punishment is related to the adoption of behaviors of greater or lesser openness and involvement regarding pain, and therefore to its acceptance. Furthermore, sensitivity to punishment is also associated with less social activity and a lower probability of social support (54), with the latter being a highly important variable in coping with chronic pain $(55,56)$.

Related to this last point, research has focused its attention on interpersonal relationships involving participants with chronic pain, and more specifically within the family setting. According to the theory of operant conditioning, the immediate environment's response has the ability to promote behaviors 
of pain or well-being among participants with chronic pain (57). Many studies have reported that solicitous responses (e.g., expressions of support or concern, or instrumental support for the pain behavior) and punishing responses (e.g., expressions of frustration or irritation toward the pain behavior) by significant people close to the patient are linked to an increase in pain, lower levels of activity, more pain behaviors, more visits to the doctor, and greater disability (58-67). This means that significant people's reaction to these participants' pain behaviors may have an indirect impact on pain acceptance processes. Furthermore, relatively large studies involving participants with chronic pain have found a strong and negative relationship between solicitous and punishing responses and pain acceptance (68), maintaining its predictor value even a year after the medical intervention (69).

The information provided as theoretical underpinnings has informed this study designed to examine the relationship between pain-related anxiety, sensitivity toward punishment and reinforcement, significant people's response to pain behaviors, and its predictive capacity in terms of pain acceptance, due to the relationship shown by these variables in the aforementioned studies. Results will inform treatment decision-making and the standard of psychological care provided to people with chronic pain.

\section{METHODS}

\section{Participants}

The study was approved by the Research and Ethics Committee of CEIC Hospital Clínico San Carlos in Spain. Subjects eligible for the study were patients with rheumatoid arthritis $(n=62)$ participants who were undergoing treatment in the Department of Rheumatology at the hospital and at the Madrid Association of Participants with Rheumatoid Arthritis (AMAPAR, in its Spanish acronym). All the data required for the study were gathered between December 2015 and February 2017. Subjects were screened by phone about their interest of participation in the study, only participants with higher interest were selected for evaluation. Subjects who indicated that they were medically healthy, other than rheumatoid arthritis, aged $\geq 18$ years willingness to give consent and participate in the study, were asked to meet the lead researcher on a face-to-face interview for individual assessment. The assessment was conducted individually in a single session by the same assessor, without any limit of time. On average, each session took one and a half hours. During the evaluation process participants were excluded if they had: (1) a history of psychiatric disorder such as major depressive disorder, obsessive-compulsive disorder or anxiety generalized disorder schizophrenia; (2) lack of motivation to complete the self-report measures; (3) or high levels of alcohol/substance abuse. Female patients who were pregnant or lactating women were not grounds for exclusion. The participants who refused to complete data on all self-report measures listed below were excluded from final sample $(n=6)$. Participant characteristics are presented in a table in results section (see Table 1). The study design is presented in Figure 1.
TABLE 1 | Sociodemographic characteristics and clinical variables of the study participants.

\begin{tabular}{|c|c|c|}
\hline Characteristic & Frequency $(n)$ & Percentage (\%) \\
\hline \multicolumn{3}{|l|}{ Sex } \\
\hline Female & 13 & 21 \\
\hline Male & 49 & 79 \\
\hline Age in years $(M, S D)$ & $53.2 \pm(11.2)$ & \\
\hline \multicolumn{3}{|l|}{ Marital status } \\
\hline Single & 15 & 24.2 \\
\hline Married & 31 & 50.0 \\
\hline Widowed & 3 & 4.8 \\
\hline Divorced & 7 & 11.3 \\
\hline Separated & 6 & 9.7 \\
\hline \multicolumn{3}{|l|}{ Education level } \\
\hline Primary & 7 & 11.3 \\
\hline EGB or equivalent & 7 & 11.3 \\
\hline Technical and vocational & 10 & 16.1 \\
\hline Senior high school & 17 & 27.4 \\
\hline University & 15 & 24.2 \\
\hline Higher education & 3 & 4.8 \\
\hline Unregulated studies & 3 & 4.8 \\
\hline \multicolumn{3}{|l|}{ Socioeconomic status } \\
\hline Low & 13 & 21 \\
\hline Medium & 43 & 69.3 \\
\hline High & 6 & 9.7 \\
\hline \multicolumn{3}{|l|}{$\begin{array}{l}\text { Time elapsed since the first medical } \\
\text { diagnosis }\end{array}$} \\
\hline Less than a year & 4 & 6.4 \\
\hline Less than 3 years & 4 & 6.5 \\
\hline Less than 5 years & 2 & 3.2 \\
\hline Between 5 and 10 years & 15 & 24.2 \\
\hline More than 10 years & 37 & 59.7 \\
\hline \multicolumn{3}{|l|}{ Pharmacological treatment } \\
\hline None & 1 & 1.6 \\
\hline $\begin{array}{l}\text { Biological agents (e.g., Infliximab, } \\
\text { Abatacept, etc.). }\end{array}$ & 2 & 3.2 \\
\hline FAMES (e.g., Metotrexato). & 1 & 1.6 \\
\hline Corticosteroids & 0 & 0 \\
\hline Anti-inflammatory drugs & 1 & 1.6 \\
\hline Analgesic drugs & 0 & 0 \\
\hline Others & 2 & 3.2 \\
\hline Several of the above & 55 & 88.7 \\
\hline
\end{tabular}

$M$, mean; SD, standard deviation.

\section{Ethical Statement}

The study protocol was approved by the Research and Ethics Committee of CEIC Hospital Clínico San Carlos in Spain, registration number 15.531-E. Date of communication: 10 December 2015. All participants signed a consent form after been informed about eligibility criteria and study procedures. The lead investigator monitored the data collection and informed consent process. Only participants who completed data for all self-report measures listed below were included in the sample and taken into consideration for the statistical analyses. Those who 


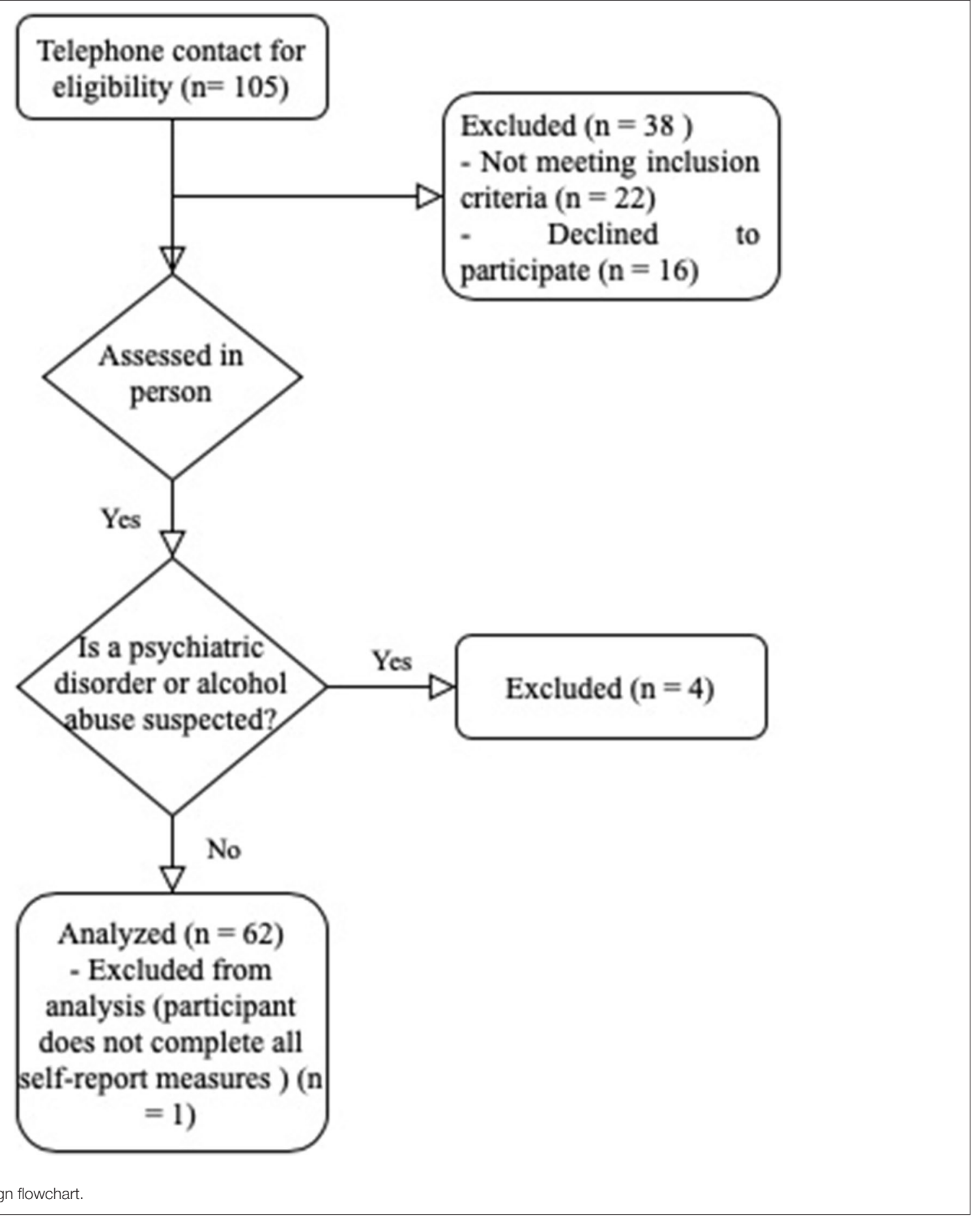

FIGURE 1 | Study design flowchart.

did not meet the conditions of eligibility previously mentioned were discarded.

\section{Procedure and Self-Report Measures}

The self-report measures were administered on a face-to-face basis at the Department of Rheumatology at the Hospital Clínico San Carlos in Madrid (Spain) and at AMAPAR. Only five participants were assessed by videoconferencing via Skype. The participants were invited to take part in the study, and once they had voluntarily agreed to do so, they left their phone number for the initial contact. The lead researcher subsequently contacted the interested parties to give them information on the study and arrange a meeting. The assessment was conducted individually in a single session, without any limit of time, and always involved the same assessor. During the appointment, the participants signed the informed consent form and completed a 
socio-demographic questionnaire, answering questions about the nature of the pain, the time elapsed since their first diagnosis, and the medical treatment they were following. Finally, they also completed a series of self-report measures on the psychological variables to be studied, as described in what follows.

- CPAQ. Chronic Pain Acceptance Questionnaire [(16): Spanish version by Menéndez (70)]. It consists of 20 items that assess the acceptance of pain in participants with chronic pain. The questionnaire has two subscales: openness to pain and involvement in activities. The former refers to an individual's willingness to experience pain without putting up any resistance, while the latter assesses an individual's ability to take part in activities despite the pain. The answers involve a Likert-type scale from 0 (never true) to 6 (always true). Our sample recorded suitable levels of internal consistency reliability for the total scale (Cronbach's alpha $=0.690$ ), according to the criteria proposed by Prieto (71).

- PASS-20. Pain Anxiety Symptoms Scale (72). This scale explores anxiety responses to pain: fear, escape/avoidance, physiological anxiety, and cognitive anxiety. It consists of 20 items with Likert-type answers ranging from 1 (never) to 5 (always). Our sample has recorded suitable criteria for internal consistency reliability through Cronbach's alpha coefficient (presented in brackets) for its five component subscales: fear (0.772), escape/avoidance (0.649), physiological anxiety (0.598), cognitive anxiety (0.811), and overall scale (0.880). They are suitable according to Prieto's criteria (71).

- SPSRQ. The Sensitivity to Punishment and Sensitivity to Reward Questionnaire (73). This is a self-report measure consisting of 48 items with a dichotomous (Yes/No) answer format. It is divided into two subscales, each with 24 items: sensitivity to reward (STR) (behaviors focusing on the search for reinforcers, such as the search for sensations, money, or power), and sensitivity to punishment (SP) (behaviors designed to avoid aversive stimuli or negative consequences, due to the possibility of harm or failure). Through Cronbach's alpha coefficient (presented in brackets), this study has recorded acceptable levels of reliability for STR (0.725) and good ones for SP (0.825), which were appropriate according to Prieto's criteria (71).

- WHYMPI. The West Haven-Yale Multidimensional Pain Inventory [(74); Spanish version by Ferrer (75)]. The study applied the second domain of the questionnaire corresponding to the subscale that assesses the reinforcing and punishing responses provided by the caregivers in response to a patient's pain behaviors. This section consists of 14 items with a Likert-type response format ranging from 0 (never) to 6 (very often). The measure has recorded good levels of reliability in our sample (Cronbach's alpha $=0.842$ ) according to the criteria proposed by Prieto (71).

\section{Data Analysis}

The data were coded and analyzed using version 25.0 of the SPSS statistical package. The goals considered here involved conducting multiple stepwise linear regression exploratory analyses. The predictor variables used were cognitive anxiety, reinforcement sensitivity, sensitivity to punishment, the reinforcements and punishments administered by the patient's carers in response to pain behaviors, as well as the variables to be controlled (age, time elapsed in months since the first symptoms of pain, socioeconomic status, and the current medical treatment being received). The acceptance of pain was used as the dependent variable or criterion variable. A series of prior tests were carried out to ensure compliance with the assumptions of normality, revealing a suitable distribution of the residuals. In terms of homoscedasticity, the Durbin-Watson results (1.656) are within the recommended range $(2 \pm 0.5)$. The tolerance values for the variables introduced were below 0.10 , dismissing any problems of collinearity. These statistics therefore tell us that these data are suitable for a linear regression analysis.

\section{RESULTS}

\section{Sample Characteristics}

The sample consisted of 62 participants $(13 \mathrm{M} / 49 \mathrm{~F})$, the mean age was 53.24 ( $\mathrm{SD}=11.29)$, ranging between 25 and 77 . Half of the participants were married or in a long-term partnership (50\%), followed by those that were single $(24.2 \%)$, divorced $(11.3 \%)$, separated (9.7\%), and finally, widowed (4.8\%). Regarding their educational status, many participants had completed primary ( $n=7,11,3 \%)$, secondary school $(n=17,27,4 \%)$, or university $(n=18,29 \%)$ studies. About a third of them had completed some type of tertiary or vocational education $(n=10,16.1 \%)$. Altogether, 69.3\% reported medium incomes ( $n=43,69.3 \%)$. The distribution of the time elapsed since the first medical diagnosis in our sample was less than a year $(n=4,6.4 \%)$, $<3$ years $(n=4,6.5 \%),<5$ years $(n=2,3.2 \%)$, between 5 and 10 years $(n=15,24.2 \%)$, and more than 10 years ( $n=37,59.7 \%)$. Most of the participants were following a pharmacological treatment based on FAMES $(n=1,1.6 \%)$, antiinflammatory medication $(n=1,1.6 \%)$, biological medication $(n$ $=2,3.2 \%)$, others $(n=2,3.2 \%)$, and several of these $(n=55$, $88.7 \%$ ). Only $1.6 \%$ were not receiving any medical treatment. The characteristics of the study participants, based on sociodemographics and relevant clinical variables are summarized in Table 1.

\section{Multiple Regression Analysis of the Acceptance of Multiple Regression Analysis With Acceptance as Dependent Variable}

With a view to meeting this study's overriding goals of studying the relationships between predictor variables (anxiety toward pain, sensitivity to pain and to reinforcement, and the responses of significant persons to pain behaviors) on the dependent variable (pain acceptance), a multiple stepwise linear regression exploratory analysis has been conducted.

Table 2 shows the results of the correlations between the predictor variables and the acceptance of pain (CPAQ). The analyses revealed a model that added significant persons' punishing responses $\left(\Delta R^{2}=0.045\right)$ when facing pain behaviors 
TABLE 2 | Multiple stepwise linear regression analysis of pain-related anxiety, sensitivity to punishment and reinforcement, and the punishing responses of significant persons toward pain behaviors, on the acceptance of pain*.

\begin{tabular}{|c|c|c|c|c|c|c|c|c|c|c|}
\hline \multirow[t]{2}{*}{ Step } & \multirow[t]{2}{*}{ Predictors } & \multirow[b]{2}{*}{$B$} & \multirow[b]{2}{*}{$\beta$} & \multirow[b]{2}{*}{$t$} & \multirow[b]{2}{*}{$p$} & \multirow[b]{2}{*}{$\mathbf{R}$} & \multicolumn{4}{|c|}{ Regression model } \\
\hline & & & & & & & $\mathbf{R}^{2}$ & $\Delta \mathbf{R}^{2}$ & $F$ & $P$ \\
\hline 1 & $\begin{array}{l}\text { Constant } \\
\text { PASS_20_total }\end{array}$ & $\begin{array}{r}96.226 \\
-0.681\end{array}$ & $-0.605^{\star \star \star}$ & $\begin{array}{r}18.406 \\
-5.891\end{array}$ & $\begin{array}{l}0.00 \\
0.00\end{array}$ & 0.36 & 0.356 & 0.366 & $34.698^{\star \star *}$ & 0.000 \\
\hline 2 & $\begin{array}{l}\text { Constant } \\
\text { Pass_20_total } \\
\text { Reinforcement sensitivity }\end{array}$ & $\begin{array}{l}97.954 \\
-0.548 \\
-1.098\end{array}$ & $\begin{array}{l}-0.488^{\star \star \star} \\
-0.272^{\star}\end{array}$ & $\begin{array}{r}19.346 \\
-4.462 \\
-2.489\end{array}$ & $\begin{array}{l}0.00 \\
0.00 \\
0.016\end{array}$ & 0.42 & 0.407 & 0.060 & $21.948^{\star \star \star}$ & 0.000 \\
\hline 3 & $\begin{array}{l}\text { Constant } \\
\text { Pass_20_total } \\
\text { Reinforcement sensitivity } \\
\text { Whympi punishment }\end{array}$ & $\begin{array}{r}99.688 \\
-0.563 \\
-1.086 \\
-0.592\end{array}$ & $\begin{array}{l}-0.501^{\star \star \star} \\
-0.269^{\star} \\
-0.212^{\star}\end{array}$ & $\begin{array}{l}20.083 \\
-4.722 \\
-2.541 \\
-2.222\end{array}$ & $\begin{array}{l}0.00 \\
0.00 \\
0.14 \\
0.030\end{array}$ & 0.47 & 0.444 & 0.045 & $17.255^{\star \star \star}$ & 0.000 \\
\hline
\end{tabular}

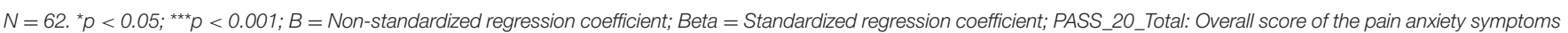

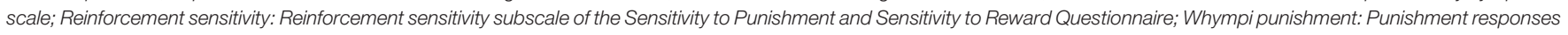
to pain behavior in the second domain of the West Haven-Yale Multidimensional Pain Inventory.

to other variables, such as pain-related anxiety $\left(\Delta \mathrm{R}^{2}=0.060\right)$ and reinforcement sensitivity $\left(\Delta \mathrm{R}^{2}=0.366\right)$. This led to a statistically significant model $(F=17.255, p \leq 0.01)$ that explained $44 \%$ of the variance on the dependent variable (Adjusted $\mathrm{R}^{2}=0.444$ ). All the correlations that feature in the model were significant when predicting pain-related anxiety, and reached the statistical criterion $p \leq 0.05$ required to do so. The linear regression analyses reveal a negative and significant correlation between the three predictors and the dependent variable, recording an effect size that varies from small to medium ranges according to Cohen's criteria (76).

\section{DISCUSSION}

The results presented here reveal that emotional variables such as pain-related anxiety, reinforcement sensitivity, and punishing responses toward pain behaviors by significant people for the patient accurately predict the individual's predisposition to accept pain. As noted, the scope of these relationship has generally been small or moderate. Regression analyses have provided us with a more profound understanding of the relationships between these variables described in the literature.

Pain-related anxiety has proven to be the best predictor of the acceptance of pain. The results are consistent with the findings reported by other scholars on a negative and robust correlation between pain-related anxiety and the components of its acceptance $(11-13,21,35-37)$. This therefore highlights the importance that pain-related anxiety might have as a variable linked to the acquisition of fear and escape or avoidance behaviors in the face of pain, as reported by other scholars in the literature reviewed (39-41). According to pain-avoidance models $(77,78)$, escape behavior impedes an elaborative processing of the stimuli being avoided (e.g., sensorial aspects of pain, thoughts, emotions or sensations) (79), which leads to the acquisition of fear related to the pain itself, and a biased interpretation of the symptoms as threatening $(25,80)$. This means that if the patient is experiencing high levels of anxiety, it is reasonable to assume that this emotion is going to play an important role in the way the patient suffers and copes with the illness and, therefore, in their clinical treatment.
Our findings show that the STR variable is linked to a greater predisposition toward the acceptance of pain in the presence of higher levels of STR. The results are consistent with the findings reported in other studies, which have noted this variable's importance in participants with chronic pain (47, 53). Nevertheless, prior studies have indicated that participants with chronic pain are expected to have a greater level of activation in the BIS, and a lower one in the BAS, with a greater presence of avoidance behaviors (47-51). Knowing that the activation of both systems is related to SP and STR (81), we expected to find a direct and significant correlation between STR or an indirect correlation between PS and pain acceptance. Nevertheless, these results can be explained when we consider that the perception of reinforcement varies for each person and depends on their psychological state, their values and their goals (82). For example, it is logical that someone with a high STR and greater impulsiveness is more motivated to achieve goals and assign behavioral resources accordingly, although for such a person it might be harder to accept that the pain, or the incapacity associated with it, no longer permits them to do so. It therefore seems probable that this individual may cope by seeking immediate relief for their symptoms in order to resolve the interference in the short term; in other words, the individual will mobilize behavioral resources looking for negative reinforcement, and they are more than likely to record more escape or avoidance behaviors. It therefore seems reasonable to contend that the higher the STR and the greater the impulsiveness, the lower the predisposition to accept pain. Nonetheless, future researchers will be tasked with clarifying this variable's role regarding acceptance and coping in participants with chronic pain.

This study has also uncovered a negative and significant correlation between the punishing responses toward pain behaviors shown by the patient's carers and pain acceptance. These results coincide with other studies that predicted a worse adjustment to pain in the presence of adverse contingencies for the patient $(58,59,62,66)$. The results also coincide with the findings made by McCraken (68), who has reported that the punishing responses of significant people are negatively associated with the acceptance of pain. Therefore, as noted earlier, 
the social support of significant persons for pain behaviors seems to be a highly influential variable in acceptance processes in contexts of chronic pain. The paucity of studies on this matter calls for further research designed to extend the information on the relationship between these two variables.

The results forthcoming here prompt us to make a series of suggestions that could help to improve the care provided for these participants. Pain-related anxiety and reinforcement sensitivity are variables to be considered during the assessment process. Whenever high scores are observed in any of these variables, it would be advisable to use some technique (e.g., cognitive restructuring) to work on cognitive aspects or even consider the possibility of a more traditional intervention for correcting a mistaken interpretation of the symptoms, reduce the perception of threat, and boost active coping with the illness, as in Cognitive Behavioral Therapy (CBT), which has proven to be extremely effective in cases of chronic pain [e.g., (83-85)]. In the case of low scores for these variables, the initial choice of treatment could involve any intervention based on third-generation therapies, as both ACT and MBIs have proven to be effective in pain contexts $(33,86-88)$. The results obtained also refer to the importance of providing families with accurate information on the way patient's behave when dealing with pain and their relationship with the treatment, whereby they can support the patient in a non-interfering manner.

These results and the aforementioned conclusions should be considered within the context of some of their limitations. Firstly, the sample used here involved discarding several participants that did not meet the inclusion criteria, and the final cohort consisted solely of participants with rheumatoid arthritis. Future research should study the relationship between these variables and other groups of participants with chronic pain. Moreover, the final sample is small, particularly in the case of males, so other researchers are advised to employ broader samples in the future with a view to comparing results. It is also important to talk about methodological issues arising from the self-report measure used to assess the main carers' responses to their participants' pain behaviors. This instrument rates the carers' responses based on the individual's own subjective opinion. This perception may be influenced by other psychological variables, which means these data should be interpreted with some caution.

\section{CONCLUSIONS}

In sum, variables such as pain-related anxiety, STR, and the punishing responses of significant people for the patient predict

\section{REFERENCES}

1. International Classification of Diseases for Mortality and Morbidity Statistics, 11th Revision (ICD-11). (2018). Available online at: https://icd.who.int/ browse11/l-m/en\#/http://id.who.int/icd/entity/1581976053

2. Breivik H, Collett B, Ventafridda V, Cohen R, Gallacher D. Survey of chronic pain in Europe: prevalence, impact on daily life, and treatment. Eur J Pain. (2006) 10:287-333. doi: 10.1016/j.ejpain.2005.06.009 a lower acceptance of pain in participants with chronic pain. We may therefore infer the convenience of taking them into consideration during the assessment process in the first clinical contacts. In turn, prior knowledge of these variables may inform the decision-making on the intervention to be performed in each case, which could improve the efficacy or success of this care. Based on the results obtained, there is a need to investigate these variables in relation to the components of the acceptance of pain, given the part they play in the treatment to be followed with these participants.

\section{DATA AVAILABILITY STATEMENT}

The original contributions presented in the study are included in the article/Supplementary Material, further inquiries can be directed to the corresponding author.

\section{ETHICS STATEMENT}

The studies involving human participants were reviewed and approved by CEIC Hospital Clínico San Carlos. The patients/participants provided their written informed consent to participate in this study.

\section{AUTHOR CONTRIBUTIONS}

LP contributed in the conception, design of the study, acquired the data, analyzed and interpreted the patient data, drafted the article and overseed the final version of the article before submission, and was a major contributor in writing the manuscript. MP-N had a relevant role in the conceptualization of the study, analysis and interpretation of the data, and drafting the article. MR contributed in the conception and design of the study. LR-R and LL contributed to acquisition of data. All authors read and approved the final manuscript.

\section{ACKNOWLEDGMENTS}

We wish to thank all the participants involved in the study.

\section{SUPPLEMENTARY MATERIAL}

The Supplementary Material for this article can be found online at: https://www.frontiersin.org/articles/10.3389/fpsyt. 2020.554990/full\#supplementary-material
3. Croft P, Blyth FM, van der Windt D. Chronic Pain Epidemiology: From Aetiology to Public Health. New York, NY: Oxford University Press (2010).

4. Elliott AM, Smith BH, Penny KI, Smith WC, Chambers WA. The epidemiology of chronic pain in the community. Lancet. (1999) 354:1248-52. doi: 10.1016/S0140-6736(99)03057-3

5. Gureje O, Von Korff M, Simon GE, Gater R. Persistent pain and wellbeing: a world health organization study in primary care. JAMA. (1998) 280:147-51. doi: 10.1001/jama.280.2.147 
6. Langley PC, Ruiz-Iban MA, Molina JT, De Andres J, Castellón JRG-E. The prevalence, correlates and treatment of pain in Spain. J Med Econ. (2011) 14:367-80. doi: 10.3111/13696998.2011.583303

7. McQuay H. Help and hope at the bottom of the pile. BMJ. (2008) 336:954-5. doi: 10.1136/bmj.39520.699190.94

8. Phillips CJ. Economic burden of chronic pain. Expert Rev Pharmacoecon Outcomes Res. (2006) 6:591-601. doi: 10.1586/14737167.6.5.591

9. Phillips CJ. The cost and burden of chronic pain. Rev Pain. (2009) 3:2-5. doi: 10.1177/204946370900300102

10. Goldberg DS, McGee SJ. Pain as a global public health priority. BMC Public Health. (2011) 11:770. doi: 10.1186/1471-2458-11-770

11. McCracken LM. Learning to live with the pain: acceptance of pain predicts adjustment in persons with chronic pain. Pain. (1998) 74:21-7. doi: 10.1016/S0304-3959(97)00146-2

12. McCracken LM, Carson JW, Eccleston C, Keefe FJ. Acceptance and change in the context of chronic pain. Pain. (2004) 109:4-7. doi: 10.1016/j.pain.2004.02.006

13. McCracken LM, Eccleston C. Coping or acceptance: what to do about chronic pain? Pain. (2003) 105:197-204. doi: 10.1016/S0304-3959(03)00202-1

14. McCracken LM, Vowles KE. Acceptance of chronic pain. Curr Pain Headache Rep. (2006) 10:90-4. doi: 10.1007/s11916-006-0018-y

15. McCracken LM, Vowles KE. A prospective analysis of acceptance of pain and values-based action in patients with chronic pain. Health Psychol. (2008) 27:215. doi: 10.1037/0278-6133.27.2.215

16. McCracken LM, Vowles KE, Eccleston C. Acceptance of chronic pain: component analysis and a revised assessment method. Pain. (2004) 107:159-66. doi: 10.1016/j.pain.2003.10.012

17. Viane I, Crombez G, Eccleston C, Poppe C, Devulder J, Van Houdenhove B, et al. Acceptance of pain is an independent predictor of mental well-being in patients with chronic pain: empirical evidence and reappraisal. Pain. (2003) 106:65-72. doi: 10.1016/S0304-3959(03)00291-4

18. Carvalho SA, Gillanders D, Palmeira L, Pinto-Gouveia J, Castilho P. Mindfulness, selfcompassion, and depressive symptoms in chronic pain: the role of pain acceptance. J Clin Psychol. (2018) 74:2094-106. doi: 10.1002/jclp.22689

19. Evers AW, Kraaimaat FW, van Lankveld W, Jongen PJ, Jacobs JW, Bijlsma JW. Beyond unfavorable thinking: the illness cognition questionnaire for chronic diseases. J Consult Clin Psychol. (2001) 69:1026. doi: 10.1037/0022-006X.69.6.1026

20. Kratz AL, Davis MC, Zautra AJ. Pain acceptance moderates the relation between pain and negative affect in female osteoarthritis and fibromyalgia patients. Ann Behav Med. (2007) 33:291-301. doi: 10.1007/BF02879911

21. McCracken LM, Eccleston C. A prospective study of acceptance of pain and patient functioning with chronic pain. Pain. (2005) 118:164-9. doi: 10.1016/j.pain.2005.08.015

22. Pinto-Gouveia J, Costa J, Marôco J. The first 2 years of rheumatoid arthritis: the influence of acceptance on pain, physical limitation and depression. J Health Psychol. (2015) 20:102-12. doi: 10.1177/1359105313499807

23. Viane I, Crombez G, Eccleston C, Devulder J, De Corte W. Acceptance of the unpleasant reality of chronic pain: effects upon attention to pain and engagement with daily activities. Pain. (2004) 112:282-8. doi: 10.1016/j.pain.2004.09.008

24. Wicksell RK, Melin L, Olsson GL. Exposure and acceptance in the rehabilitation of adolescents with idiopathic chronic pain-a pilot study. Eur J Pain. (2007) 11:267-74. doi: 10.1016/j.ejpain.2006.02.012

25. Vowles KE, McCracken LM. Acceptance and values-based action in chronic pain: a study of treatment effectiveness and process. J Consult Clin Psychol. (2008) 76:397-407. doi: 10.1037/0022-006X.76.3.397

26. Dahl J, Wilson KG, Nilsson A. Acceptance and commitment therapy and the treatment of persons at risk for long-term disability resulting from stress and pain symptoms: a preliminary randomized trial. Behav Ther. (2004) 35:785-801. doi: 10.1016/S0005-7894(04)80020-0

27. Hayes S, Strosahl K, Wilson K. Acceptance and Commitment Therapy: Understanding and Treating Human Suffering. New York, NY: Guilford Press (1999).

28. Kabat-Zinn J, Lipworth L, Burney R. The clinical use of mindfulness meditation for the self-regulation of chronic pain. J Behav Med. (1985) 8:163-90. doi: 10.1007/BF00845519
29. Hann KE, McCracken LM. A systematic review of randomized controlled trials of acceptance and commitment therapy for adults with chronic pain: outcome domains, design quality, and efficacy. J Contextual Behav Sci. (2014) 3:217-27. doi: 10.1016/j.jcbs.2014.10.001

30. Hughes LS, Clark J, Colclough JA, Dale E, McMillan D. Acceptance and commitment therapy (ACT) for chronic pain. Clin J Pain. (2017) 33:552-68. doi: 10.1097/AJP.0000000000000425

31. Veehof MM, Oskam M-J, Schreurs KM, Bohlmeijer ET. Acceptance-based interventions for the treatment of chronic pain: a systematic review and meta-analysis. Pain. (2011) 152:533-42. doi: 10.1016/j.pain.2010.11.002

32. Bawa FLM, Mercer SW, Atherton RJ, Clague F, Keen A, Scott NW, et al. Does mindfulness improve outcomes in patients with chronic pain? Systematic review and meta-analysis. Br J Gen Pract. (2015) 65:e387-400. doi: 10.3399/bjgp15X685297

33. Hilton L, Hempel S, Ewing BA, Apaydin E, Xenakis L, Newberry S, et al. Mindfulness meditation for chronic pain: systematic review and metaanalysis. Ann Behav Med. (2017) 51:199-213. doi: 10.1007/s12160-016-9844-2

34. Quintana M, Rincón Fernández ME. Eficacia del entrenamiento en mindfulness para pacientes con fibromialgia. Clín Salud. (2011) 22:5167. doi: $10.5093 / \mathrm{cl} 2011 \mathrm{v} 22 \mathrm{n} 1 \mathrm{a} 4$

35. Asmundson GJ, Kuperos JL, Norton GR. Do patients with chronic pain selectively attend to pain-related information?: preliminary evidence for the mediating role of fear. Pain. (1997) 72:27-32. doi: 10.1016/S0304-3959(97)00010-9

36. McCracken LM. A contextual analysis of attention to chronic pain: what the patient does with their pain might be more important than their awareness or vigilance alone. J Pain. (2007) 8:230-6. doi: 10.1016/j.jpain.2006.08.004

37. McCracken LM, Eccleston C. A comparison of the relative utility of coping and acceptance-based measures in a sample of chronic pain sufferers. Eur $J$ Pain. (2006) 10:23-9. doi: 10.1016/j.ejpain.2005.01.004

38. Reiss S. Theoretical perspectives on the fear of anxiety. Clin Psychol Rev. (1987) 7:585-96. doi: 10.1016/0272-7358(87)90007-9

39. Norton PJ, Asmundson GJ. Anxiety sensitivity, fear, and avoidance behavior in headache pain. Pain. (2004) 111:218-23. doi: 10.1016/j.pain.2004.06.018

40. Stewart SH, Asmundson GJ. Anxiety sensitivity and its impact on pain experiences and conditions: a state of the art. Cogn Behav Ther. (2006) 35:185-8. doi: 10.1080/16506070601090457

41. Zvolensky MJ, Goodie JL, McNeil DW, Sperry JA, Sorrell JT. Anxiety sensitivity in the prediction of pain-related fear and anxiety in a heterogeneous chronic pain population. Behav Res Ther. (2001) 39:68396. doi: 10.1016/S0005-7967(00)00049-8

42. Hayes SC, Luoma JB, Bond FW, Masuda A, Lillis J. Acceptance and commitment therapy: model, processes and outcomes. Behav Res Ther. (2006) 44:1-25. doi: 10.1016/j.brat.2005.06.006

43. Gray JA. The psychophysiological basis of introversion-extraversion. Behav Res Ther. (1970) 8:249-66. doi: 10.1016/0005-7967(70)90069-0

44. Gray JA. The neuropsychology of anxiety. Issues Ment Health Nurs. (1985) 7:201-28. doi: 10.3109/01612848509009455

45. Jensen M, Ehde D, Day M. The behavioral activation and inhibition systems: implications for understanding and treating chronic pain. J Pain. (2016) 17:529.e1-18. doi: 10.1016/j.jpain.2016.02.001

46. García JAB. Actividad de los sistemas de aproximación e inhibición conductual y psicopatología. Annu Clin Health Psychol. (2010) 6:61-5.

47. Becerra-García JA, Robles Jurado MJ. Behavioral approach system activity and self-reported somatic symptoms in fibromyalgia: an exploratory study. Int $J$ Rheum Dis. (2014) 17:89-92. doi: 10.1111/1756-185X.12034

48. Jensen MP, Tan G, Chua SM. Pain intensity, headache frequency, and the behavioral activation and inhibition systems. Clin J Pain. (2015) 31:1068-74. doi: 10.1097/AJP.0000000000000215

49. Jensen MP, Solé E, Castarlenas E, Racine M, Roy R, Miró J, et al. Behavioral inhibition, maladaptive pain cognitions, and function in patients with chronic pain. Scand J Pain. (2017) 17:41-8. doi: 10.1016/j.sjpain.2017.07.002

50. Serrano-Ibáñez ER, López-Martínez AE, Ramírez-Maestre C, Esteve $\mathrm{R}$, Jensen MP. The behavioral inhibition and activation systems and function in patients with chronic pain. Pers Individ Differ. (2019) 138:56-62. doi: 10.1016/j.paid.2018.09.021

51. Serrano-Ibáñez ER, Ramírez-Maestre C, Esteve R, López-Martínez AE. The behavioural inhibition system, behavioural activation system and 
experiential avoidance as explanatory variables of comorbid chronic pain and posttraumatic stress symptoms. Eur J Psychotraumatol. (2019) 10:1581013. doi: 10.1080/20008198.2019.1581013

52. Corr PJ, Matthews G. The Cambridge Handbook of Personality Psychology. Cambridge: Cambridge University Press (2009).

53. Elvemo N, Landrø NI, Borchgrevink PC, Håberg A. Reward responsiveness in patients with chronic pain. Eur J Pain. (2015) 19:1537-43. doi: 10.1002/ejp.687

54. Watson J, Nesdale D. Rejection sensitivity, social withdrawal, and loneliness in young adults. J Appl Soc Psychol. (2012) 42:1984-2005. doi: $10.1111 /$ j.1559-1816.2012.00927.x

55. Jamison RN, Virts KL. The influence of family support on chronic pain. Behav Res Ther. (1990) 28:283-7. doi: 10.1016/0005-7967(90)90079-X

56. Evers AW, Kraaimaat FW, Geenen R, Jacobs JW, Bijlsma JW. Pain coping and social support as predictors of long-term functional disability and pain in early rheumatoid arthritis. Behav Res Ther. (2003) 41:1295-310. doi: 10.1016/S0005-7967(03)00036-6

57. Fordyce W, Fowler R, Lehmann J, De Lateur BJ, Sand P, Trieschmann R. Operant conditioning in the treatment of chronic pain. Arch Phys Med Rehabil. (1973) 54:399-408.

58. Block AR, Kremer EF, Gaylor M. Behavioral treatment of chronic pain: the spouse as a discriminative cue for pain behavior. Pain. (1980) 9:243-52. doi: 10.1016/0304-3959(80)90011-1

59. Boothby JL, Thorn BE, Overduin LY, Ward LC. Catastrophizing and perceived partner responses to pain. Pain. (2004) 109:500-6. doi: 10.1016/j.pain.2004.02.030

60. Flor H, Kerns RD, Turk DC. The role of spouse reinforcement, perceived pain, and activity levels of chronic pain patients. J Psychosom Res. (1987) 31:251-9. doi: 10.1016/0022-3999(87)90082-1

61. Lousberg R, Schmidt AJ, Groenman NH. The relationship between spouse solicitousness and pain behavior: searching for more experimental evidence. Pain. (1992) 51:75-9. doi: 10.1016/0304-3959(92)90011-Y

62. Raichle KA, Romano JM, Jensen MP. Partner responses to patient pain and well behaviors and their relationship to patient pain behavior, functioning, and depression. Pain. (2011) 152:82-8. doi: 10.1016/j.pain.2010.09.015

63. Romano JM, Jensen MP, Turner JA, Good AB, Hops H. Chronic pain patientpartner interactions: further support for a behavioral model of chronic pain. Behav Ther. (2000) 31:415-40. doi: 10.1016/S0005-7894(00)80023-4

64. Paulsen JS, Altmaier EM. The effects of perceived vs. enacted social support on the discriminative cue function of spouses for pain behaviors. Pain. (1995) 60:103-10. doi: 10.1016/0304-3959(94)00096-W

65. Schwartz L, Jensen MP, Romano JM. The development and psychometric evaluation of an instrument to assess spouse responses to pain and well behavior in patients with chronic pain: the spouse response inventory. J Pain. (2005) 6:243-52. doi: 10.1016/j.jpain.2004.12.010

66. Vriezekolk JE, Peters AJ, van den Ende CH, Geenen R. Solicitous and invalidating responses are associated with health-care visits in fibromyalgia. Rheumatol Adv Pract. (2019) 3:rkz008. doi: 10.1093/rap/rkz008

67. Williamson D, Robinson ME, Melamed B. Pain behavior, spouse responsiveness, and marital satisfaction in patients with rheumatoid arthritis. Behav Modif. (1997) 21:97-118. doi: 10.1177/01454455970211006

68. McCracken LM. Social context and acceptance of chronic pain: the role of solicitous and punishing responses. Pain. (2005) 113:155-9. doi: 10.1016/j.pain.2004.10.004

69. Söderlund A, Löfgren M, Stålnacke B-M. Predictors before and after multimodal rehabilitation for pain acceptance and engagement in activities at a 1-year follow-up for patients with whiplash-associated disorders (WAD) a study based on the Swedish quality registry for pain rehabilitation (SQRP). Spine J. (2018) 18:1475-82. doi: 10.1016/j.spinee.2017.11.014

70. Menéndez AG, García PF, Viejo IT. Aceptación del dolor crónico en pacientes con bromialgia: adaptación del chronic pain acceptance questionnaire (CPAQ) a una muestra española. Psicothema. (2010) 22:997-1003.

71. Prieto G, Muñiz J. Un modelo para evaluar la calidad de los tests utilizados en España. Papeles Psicól. (2000) 77:65-72.
72. McCracken LM, Dhingra L. A short version of the pain anxiety symptoms scale (PASS-20): preliminary development and validity. Pain Res Manag. (2002) 7:45-50. doi: 10.1037/t61999-000

73. Torrubia R, Avila C, Moltó J, Caseras X. The sensitivity to punishment and sensitivity to reward questionnaire (SPSRQ) as a measure of Gray's anxiety and impulsivity dimensions. Pers Individ Differ. (2001) 31:83762. doi: 10.1016/S0191-8869(00)00183-5

74. Kerns R, Turk DC, Rudy, TE. The west haven-yale multidimensional pain inventory (WHYMPI). Pain. (1985) 23:345-56. doi: 10.1016/0304-3959(85)90004-1

75. Ferrer V, González R, Manassero M. El west haven yale Multidimensional pain questionnaire: un instrumento para evaluar al paciente con dolor crónico. Dolor. (1993) 8:153-60.

76. Cohen J. Statistical Power Analysis for the Behavioral Sciences. New York, NY: Routledge (2013).

77. Asmundson GJ, Norton PJ, Vlaeyen JW. Fear-avoidance models of chronic pain: an overview. Understand Treat Fear Pain. (2004) 3-24.

78. Vlaeyen JW, Linton SJ. Fear-avoidance and its consequences in chronic musculoskeletal pain: a state of the art. Pain. (2000) 85:317-32. doi: 10.1016/S0304-3959(99)00242-0

79. McCracken LM. Contextual cognitive-behavioral therapy for chronic pain. Progr Pain Res Manag. (2005) 12:53-4.

80. Siegel S. Drug tolerance, drug addiction, and drug anticipation. Curr Direct Psychol Sci. (2005) 14:296-300. doi: 10.1111/j.0963-7214.2005.00384.x

81. Gray J. The Psychology of Fear and Stress. New York, NY: Cambridge University Press (1987).

82. Carver CS, White TL. Behavioral inhibition, behavioral activation, and affective responses to impending reward and punishment: the BIS/BAS scales. J Pers Soc Psychol. (1994) 67:319. doi: 10.1037/0022-3514.67.2.319

83. Eccleston C, Crombez G. Pain demands attention: a cognitive-affective model of the interruptive function of pain. Psychol Bull. (1999) 125:35666. doi: 10.1037/0033-2909.125.3.356

84. Morley S, Shapiro DA, Biggs J. Developing a treatment manual for attention management in chronic pain. Cogn Behav Ther. (2004) 33:111. doi: $10.1080 / 16506070310001794$

85. Casey M-B, Smart KM, Hearty C, Lowry D, Doody C. Acceptance of chronic pain. Perspectives of individuals following an acceptance and commitment therapy pain management programme: an interpretative phenomenological analysis. Physiother Pract Res. (2019) 40:9-19. doi: 10.3233/ PPR-180120

86. Feliu-Soler A, Montesinos F, Gutiérrez-Martínez O, Scott W, McCracken LM, Luciano JV. Current status of acceptance and commitment therapy for chronic pain: a narrative review. J Pain Res. (2018) 11:2145-59. doi: 10.2147/JPR.S144631

87. Palao Tarrero Á, Torrijos Zarcero M, Río Md, Muñoz-Sanjosé A, Rodríguez Vega B. Intervenciones basadas en Mindfulness y compasión en dolor crónico. RIECS. (2019) 4.

88. Hervás G, Cebolla A, Soler J. Intervenciones psicológicas basadas en mindfulness y sus beneficios: estado actual de la cuestión [Mindfulness-based psychological interventions and benefits: state of the art]. Clín Salud. (2016) 27:115-24. doi: 10.1016/j.clysa.2016.09.002

Conflict of Interest: The authors declare that the research was conducted in the absence of any commercial or financial relationships that could be construed as a potential conflict of interest.

Copyright (๑) 2020 Pinel, Perez-Nieto, Redondo, Rodríguez-Rodríguez and León. This is an open-access article distributed under the terms of the Creative Commons Attribution License (CC BY). The use, distribution or reproduction in other forums is permitted, provided the original author(s) and the copyright owner(s) are credited and that the original publication in this journal is cited, in accordance with accepted academic practice. No use, distribution or reproduction is permitted which does not comply with these terms. 